\title{
Frente de Trabalho da Iniciativa Privada no Sistema Carcerário do Estado do Espírito Santo
}

\section{Work initiative of private enterprises in the correctional system of the Estate of Espirito Santo}

\author{
Fernanda Mendes Pires ${ }^{1}$
}

Márcia Prezotti Palassi²

\section{Resumo}

Neste artigo analisa-se - sob a ótica dos presos e dos responsáveis empresas em presídios - o impacto das frentes de trabalho promovidas por duas empresas privadas na ressocialização dos presos no Instituto de Readaptação Social - IRS -em Vila Velha - ES e na Penitenciária de Segurança Média II de Viana - PSME II -ES. Examinam-se, ainda, os aspectos gerenciais relativos à implantação e manutenção dessas empresas nas penitenciárias citadas. Trata-se de um estudo de caso de natureza qualitativa, em que os dados foram coletados, no ano de 2005, através de duas entrevistas semiestruturadas com os responsáveis pelas empresas privadas e dez internos - os resultados foram submetidos à análise de conteúdo proposta por Laville e Dione (1999). Eles apontam a competitividade como o principal motivo de inserção das empresas privadas no sistema penitenciário e a conservação do foco da produção na unidade prisional, sem estender o trabalho aos egressos. Na perspectiva de análise dos internos, o trabalho representa uma fuga ao ambiente carcerário e ao ócio, bem como auxílio financeiro a suas familias e qualificação. Conclui-se que os trabalhos desenvolvidos pelos internos pouco influenciam em suas pretensões de reencontro com o mercado de trabalho, mas mostram-se de extrema importância no cotidiano de cumprimento da pena.

Palavras-chave: trabalho prisional; empresa privada; ressocialização.

\section{Abstract}

This article analyzes the impact of work initiatives promoted by two private enterprises in the re-socialization of prisoners from the Social Re-adaptation Institute in Vila Velha - ES - IRS and the Prison of Medium Security II in Viana - ES - PSME II. The analysis is done from the stand point of inmates and companies' representatives in the prisons. The article also analyzes the managerial aspects related to the implementation and maintenance of these companies in the prisons. This is a qualitative case stud. Data were collected in 2005 through two semi-structured interviews with the companies' representatives in the jail and ten inmates. Competitiveness was the main reason for the companies' entry in the correctional system and for keeping the production in the prison instead of extending it to released convicts. From the inmates' perspective the job represents a way to escape from the prison atmosphere and inactivity as well as gaining work skills and financial support for their families. However, the conclusion made is that such a job has very little influence on the inmates' ability. Nevertheless, the work experience has a positive impact on the day-to-day life of the inmate.

Keywords: prison work; private enterprise; re-socialization

\footnotetext{
${ }^{1}$ Graduada em Administração pela Universidade Federal do Espírito Santo - UFES e MBA em Finanças, Auditoria e Controladoria pela Fundação Getúlio Vargas FGV. Endereço: Av. Anisio Fernandes Coelho, 585. Jardim da Penha, Vitória/ES. Cep: 29.060-670. E-mail: fermpires@gmail.com

2 Doutorado em Psicologia Social pela PUC-SP. Coordenadora do Núcleo de Estudos em Tecnologias de Gestão e Subjetividades - NETES/ Programa de PósGraduação em Administração - PPGADM - Universidade Federal do Espírito Santo - UFES. Titulação Endereço:Rua Humberto Serrano, ${ }^{\circ}{ }^{178}$, apt ${ }^{\circ}$ 901 - Praia da Costa - Vila Velha/Espírito Santo - Brasil - CEP: 29101460 - E:mail: $\underline{\text { mprezotti@ hotmail.com }}$

Artigo submetido em maio de 2007 e aceito em outubro de 2007
} 


\section{Introdução}

Drauzio Varella, em seu livro Carandiru, relata o dia-a-dia e os pensamentos dos detentos do Complexo do Carandiru, hoje inexistente, na Grande São Paulo. "Mente ociosa é moradia do demônio [...] Poderiam, também, aprender um ofício e voltar para casa com alguma perspectiva. Soltá-los mais pobres e ignorantes do que quando entraram não ajuda a reabilitá-los" (VARELLA, 1992, p.141). Em todo o livro, é perceptível a inexistência de aspirações a uma vida legítima por parte dos internos. Seus personagens, exceto um, não almejam a possibilidade de conseguir um trabalho fora da cadeia e de se reerguer de forma digna.

O livro de Varella é mais um meio de comunicação que deixa transparecer à sociedade civil como se apresentam os estabelecimentos penais no Brasil: de forma desumana e incapaz de reintegrar o condenado à sociedade. Instituíram-se em escolas do crime, em contraposição ao objetivo inicial - segundo a Lei de Execução Penal - LEP - LEI No 7.210, de 11 de Julho de 1984 (BRASIL, 2004) - de incumbência quanto à assistência material, à saúde, jurídica, educacional, social e religiosa, para que o encarcerado tenha condições de se reinserir na sociedade. O sistema prisional vive no caos e sob o descaso dos políticos e da sociedade como se o preso não fosse retornar ao convívio social. Diante desta descrença, se não for reeducado, poderá cometer novos delitos.

A inserção da iniciativa privada nos estabelecimentos carcerários, assim como de Organizações NãoGovernamentais, igrejas e órgãos de defesa dos direitos humanos, vem suprir minimamente aquilo que o governo não tem sido capaz de cumprir. Prender, manter a pessoa presa, evitar fugas, apresentar o preso à justiça e soltá-lo quando esta determinar são responsabilidades básicas do Estado, que tem se proposto a cumpri-las. Com o intuito de minimizar os efeitos da privação de liberdade a que os presos são condenados, algumas iniciativas para melhoria deste sistema têm sido criadas. $\mathrm{O}$ trabalho, assim como a religião, a educação e a recreação são maneiras de reeducá-los e trazer à vida do encarcerado valores que a sociedade livre preza (SILVA, 2001).

Para as empresas, várias são as motivações para consolidação de parcerias e inserção de frentes de trabalho nos estabelecimentos carcerários. Além disso, não há greves e reivindicações que atrapalhem a produção; a empresa não tem despesas com o local, água, luz e telefone. Ao oferecer a oportunidade de trabalho, ela exerce o papel de contribuir para que haja a reabilitação ou habilitação profissional do preso; ao mesmo tempo, diminui seus custos de produção, criando, com isso, maior capacidade frente ao mercado.

O trabalho prisional, além de proporcionar uma oportunidade às empresas, é relevante para o cumprimento da lei, para o cotidiano dos presídios, para os presos e para a sociedade. As empresas participantes aliam baixos custos indiretos a ações sociais valorizáveis por proporcionarem trabalho aos condenados, alterando, com isso, a trajetória comum das condenações no Brasil.

Objetiva-se, com este artigo, analisar o impacto das frentes de trabalho da iniciativa privada na ressocialização dos presos, bem como a possibilidade de implantação e manutenção dessas organizações no Instituto de Readaptação Social, IRS, em Vila Velha, ES, e na Penitenciária de Segurança Média II, PSME II, de Viana, ES, sob a ótica dos presos e das organizações que as promovem nos presídios. Sob a ótica da empresa, analisase a possibilidade de implantação da frente de trabalho, bem como seus aspectos gerenciais de manutenção (preparação do espaço para a produção, processo de seleção de internos, infra-estrutura, instrumentos de trabalho, capacidade de produção, tipo de material produzido, perspectiva de crescimento da produção, treinamentos, remuneração, uniformes, relacionamento entre empresa e empregados, o egresso em relação a essas empresas e o marketing social). Sob a ótica dos presos, objetiva-se descrever a percepção destes sobre o impacto da frente de trabalho no cotidiano de cumprimento da pena e em sua recolocação no mercado de trabalho.

Neste estudo, o foco está nas frentes que envolvem o trabalho com internos, condenados a pena privativa de liberdade, implantadas pela iniciativa privada nos próprios estabelecimentos penais do estado do Espírito Santo. Entre as iniciativas privadas existentes no estado, este artigo contempla o trabalho prisional da Empresa A no Instituto de Reabilitação Social de Vila Velha IRS, e da Empresa B na Penitenciária de Segurança Média II de 
Viana, PSME II. Empresas e internos são identificados por nomes fictícios ao longo deste artigo, a fim de preservar a identidade de ambos.

\section{A Prisão}

O objetivo da pena privativa de liberdade é recuperar e reclassificar socialmente o preso. No entanto, para muitos reformadores, a reclusão é criticada por ser "inútil e até nociva: é cara, mantêm os condenados na ociosidade, multiplica-lhes os vícios [...]” (FOUCAULT, 1996, p. 102)

Entende-se que a reclassificação social, ou mesmo a ressocialização, é um processo que implica aprender e, muitas vezes, desaprender vários papéis. "[...] Erwin Goffman define ressocialização como um processo mais drástico de derrubada e reconstrução de papéis individuais [...]" (JOHNSON, 1995, p. 149-150). O que requer uma instituição com forte controle - como a prisão. Assim, o apenado é obrigado a viver alheio à sociedade, e deve, nesta instituição total, receber apoio e reeducação para não mais cometer ações desviantes, tornando-se apto ao convívio diário - o que inclui, também, o relacionamento com outros indivíduos e o trabalho.

As prisões como instituições totais espalharam-se por todo o mundo, adotadas como principal meio para recuperar os presos. De acordo com Lemgruber (1997), a privação de liberdade nunca atingirá seu objetivo principal de ressocialização, pois é uma contradição o infrator reaprender a viver livre estando privado de liberdade. Nesta mesma linha de raciocínio, segundo a concepção de Foucault (1996, p. 208), a prisão "é a detestável solução, de que não se pode abrir mão".

\section{O trabalho prisional}

Junqueira (2005) considera que houve três estágios a respeito da adoção do trabalho prisional. O primeiro deles refere-se à tradição do trabalho, em especial de acordo com o calvinismo, em que é tido como uma atividade de regeneração do condenado, que permite o afastamento da vida pecaminosa gerada pelo ócio. O segundo estágio aponta o trabalho como fator punitivo; o terceiro, como fator ressocializante - concepção atualmente em voga.

Pode-se complementar a afirmação de Junqueira sobre o terceiro estágio de que o trabalho prisional é um fator ressocializante, considerando-o um "[...] fator de equilíbrio. Por meio dele os indivíduos garantem equilíbrio e melhor condicionamento psicológico, bem como melhor comprometimento social" (LEMOS; MAZZILLI; KLERING, 1998, p. 146). Porém entende-se que o trabalho adotado nas prisões não qualifica os encarcerados para o mercado de trabalho. É necessário, desse modo, reorganizar sua forma de aplicação, bem como reavaliar os trabalhos oferecidos no espaço carcerário, para que, além da ocupação da mente do apenado, haja profissionalização capaz de possibilitar ao preso um reencontro com o mercado de trabalho (LEMOS; MAZZILLI; KLERING, 1998). As atividades desenvolvidas nestas frentes de trabalho baseiam-se principalmente em princípios tayloristas da administração (LEMOS; MAZZILLI; KLERING, 1998), pois possuem características como: módulos de linha de produção com ênfase nas tarefas repetitivas, monótonas, metódicas (COSTA; BRATKOWSKI, 2004) e de baixa autonomia individual. Percebe-se que esta forma de trabalho é mais adequada ao ambiente de produção prisional (MELLO, 2005) - e tais características, como já dito, demonstram uma inaplicabilidade à realidade do mercado extramuros dos presídios.

Segundo Ribeiro e Cruz (2002) e Costa (1999), o trabalho no cárcere deve estar relacionado às experiências profissionais passadas. Ribeiro e Cruz (2002) afirmam que o trabalho deve aprimorar a habilitação profissional do detento ou, ao menos, manter os conhecimentos adquiridos antes da prisão. Do contrário, o trabalho prisional torna-se vazio e inútil, sendo utilizado apenas para reapropriação do tempo de condenação. Para Costa (1999), é necessário aplicar atividades que atendam, e mantenham, seu nível de habilidade e conhecimento; criar uma política de rotatividade entre as funções e setores, para possibilitar o crescimento e desenvolvimento deste profissional.

Apesar da preocupação em reorganizar o trabalho, apontada pelos autores Costa (1999), Ribeiro e Cruz (2002), Lemos, Mazzilli e Klering (1998) e Costa e Bratkowski (2004), há, em contrapartida, o preconceito da sociedade, que continua a negar os egressos do mercado, por mais capacitados que estejam. Muitos empresários 
são contrários ao trabalho prisional sob o argumento de que "[...] o uso de mão-de-obra encarcerada cria uma concorrência desleal em relação aos que têm de contratar pessoas no mundo livre, a preços muito mais altos [...]" (PASTORE, 2001, p. 3). Cabe ressaltar que a Organização Internacional do Trabalho, OIT, não permite a utilização do baixo valor da mão-de-obra carcerária na competitividade do mercado, por considerá-la uma prática de concorrência desleal (SILVA, 2001).

\section{Lei de Execução Penal no Brasil}

A Lei no 7.210, de Execução Penal, LEP, promulgada em 11 de julho de 1984, (BRASIL, 2004), afirma, em seu artigo $1^{\circ}$, que o principal objetivo da execução penal é efetivar as disposições de sentença e proporcionar condições para a harmônica integração social do condenado. Desde o inicio de seu vigor, sabia-se que poucas mudanças aconteceriam na prática e que suas palavras, apesar de louváveis, seriam mortas diante da realidade nacional (MIRABETE, 2002).

A LEP, em seu art. $10^{\circ}$, afirma como dever do Estado a assistência material à saúde, jurídica, educacional, social e religiosa ao preso, com objetivo de prevenção ao crime e orientação para retorno à sociedade. Na LEP, o trabalho é tomado como obrigatório para o condenado, como dever social e condição de dignidade humana, com finalidade educativa e produtiva, devendo ser adotado no espaço carcerário.

Aspectos que incentivam o estabelecimento de parcerias para o trabalho prisional são a possibilidade de uma remuneração abaixo do mercado (no mínimo três quartos do salário mínimo) e a não incidência sobre este trabalho da Consolidação das Leis do Trabalho, CLT. Portanto, os condenados não possuem, por exemplo, direito a férias e a décimo terceiro salário, e sobre as empresas não incidem outros custos diretos que onerem a produção. Em relação à jornada do trabalho prisional, estabelece-se que o trabalho deva seguir a jornada mínima de seis horas e máxima de oito, com descanso aos domingos e feriados. Além dos benefícios apresentados às empresas, o preso, a cada dia trabalhado, tem a remição de um dia da pena.

De acordo com a LEP, em seu art. 34, o trabalho prisional deve ser gerenciado por empresa pública ou fundação que objetive a formação profissional do apenado. $\mathrm{O}$ artigo $2^{\circ}$ da lei possibilita a celebração de convênios, por parte do Governo, com a iniciativa privada para oficinas de trabalho referente a setores de apoio ao presídio. Segundo Mirabete (2002), esse artigo possui o objetivo de proteger os trabalhos prisionais das empresas, que visam precipuamente o lucro, e que poderiam desvirtuá-lo de seu objetivo fundamental, que é a preparação para a reinserção do condenado no mercado de trabalho. A LEP não aborda a celebração de convênios para inserção da iniciativa privada, com fins empresariais, porém, cabe ressaltar que não a proíbe, e é sobre essa possibilidade de vínculo entre empresas privadas e o sistema carcerário que recai o foco deste estudo.

\section{Sistema Carcerário no Brasil e no Espírito Santo}

Hoje o Sistema Penitenciário Brasileiro possui uma população carcerária de 336.358 homens e mulheres e possui um déficit de vagas da ordem de 137 mil. $^{3}$ Superpopulação, ociosidade, abusos sexuais, sensacionalismo, ausência de assistência à saúde, jurídica e educacional são exemplos dos inúmeros fatores que degradam o Sistema Penitenciário Brasileiro. Diante de um meio de correção falido, como já citado, da inaplicabilidade da LEP e dos direitos humanos, é impossível considerar esse sistema como um instrumento de aplicação da justiça penal, tornando-o um dos grandes problemas a serem solucionados pelo Governo e pela sociedade brasileira.

Hoje o Sistema Carcerário do Estado do Espírito Santo constitui-se de 5.132 presos, que estão sob a responsabilidade da Secretaria de Segurança Pública e da Secretaria da Justiça, alocados em 15 unidades penais espalhadas em todo o estado, que disponibilizam 3.310 vagas. O sistema apresenta um déficit de $55,05 \%$ vagas no estado, o que provoca o superpovoamento das unidades e problemas em conseqüência deste fato ${ }^{4}$.

\footnotetext{
${ }^{3}$ Diagnóstico do Sistema Penitenciário no Brasil, em dezembro de 2004.

${ }^{4}$ Relatório da Diretoria Geral dos Estabelecimentos Penais, DIGESP, Secretaria de Estado da Justiça do Espírito Santo, dia 12 de dezembro de 2005.
} 
Deve-se considerar, ainda, que a manutenção destes presos nos estabelecimentos carcerários é onerosa para o Estado e, considerando-se o alto índice de reincidência, de $70 \%$, não vem trazendo resultados eficazes. ${ }^{5}$ De acordo com a reportagem do jornal $A$ Gazeta, publicada em 29/05/2005, o custo de manutenção de cada preso para o estado do Espírito Santo é de R \$ 1,7 mil, levando-se em consideração os gastos diretos e indiretos (FELIZ, 2005). No entanto, segundo os dados do Departamento Penitenciário Nacional, DEPEN, a média nacional é de R\$1,5 mil (CUSTO..., 2005).

\section{Formas de trabalho prisional existentes no Brasil}

Em relação ao Sistema Penitenciário Brasileiro, cabe destacar, inicialmente, que os estados possuem autonomia no gerenciamento de suas prisões. Portanto, para inserção de atividade laborais no sistema, deve-se identificar a autoridade ou órgão diretamente responsável pelo trabalho nos presídios (SILVA, 2001). Assim, para a produção no espaço prisional, a empresa necessita fixar um convênio com o Governo Estadual que pode lhe conceder permissão para atuação. No estado do Espírito Santo, os acordos são celebrados com a Secretaria da Justiça, SEJUS, e representam uma forma de acordo entre as entidades públicas ou privadas e o Poder Público para realização de objetivos com interesses em comum, em que haja mútua colaboração (DI PIETRO, 2000).

Dois são os motivos que levam a empresa a optar pelo espaço carcerário: a perspectiva de utilização de mão-deobra constante e barata e/ou a intenção de realizar filantropia. A adaptação indevida da lógica filantrópica, em sua maioria, segue a forma predatória, não sendo considerada como atuação de responsabilidade social. As trocas existentes entre o preso trabalhador e a empresa são claramente desiguais, e a responsabilidade social empresarial apenas pode tornar-se concreta se houver aplicação de outros aspectos inerentes ao trabalhador, como remuneração por produção, fornecimento de uniformes e equipamento de segurança e proteção, prestação de assistência ao preso, aos filhos e à família, inclusão em planos de assistência médica, capacitação e aperfeiçoamento, inserção em uma real cultura do trabalho e garantia de emprego após a liberdade, os quais podem vir a ser exemplos que demonstrem uma autêntica filantropia (SILVA, 2001).

As vantagens para as empresas que se estabelecem no sistema prisional referem-se, também, à infra-estrutura oferecida pela penitenciária, como espaço físico, água, energia e telefone - aspectos fundamentais na diminuição dos custos da empresa. Além de indicadores empresariais, como produtividade, o trabalho prisional possui a redução da taxa de reincidência como um ótimo indicador de eficiência social (SILVA, 2001).

Os modelos de trabalho prisional podem ser desenvolvidos extra e intramuros. As atividades externas são permitidas, porém só são aplicáveis a estabelecimentos carcerários com regime semi-aberto. A privatização é adotada com sucesso em outros países, como a Espanha, ${ }^{6}$ porém, trata-se de um modelo não permitido no Brasil. Além desse, existem outros modelos de trabalhos prisionais, como os adotados nas penitenciárias agrícolas e industriais, bem como trabalhos artesanais e a terceirização, que se torna, depois da privatização, o modelo mais arrojado de administração penitenciária. Hoje, no Brasil, tem-se um modelo de terceirização no Paraná, a Penitenciária Industrial de Guarapuava, em que uma empresa é responsável pela alimentação, assistência médica, odontológica, psicológica, jurídica, entre outros. $\mathrm{O}$ valor pago pelo governo estadual à empresa terceirizada é considerado elevado em relação à média nacional, porém o retorno deste investimento pode ser observado quando se comparam os índices de reincidência, que atingem $6 \%$ em Guarapuava, enquanto a média nacional é de 70\% (SILVA, 2001).

\section{As frentes de trabalho no Espirito Santo}

O estado do Espírito Santo, bem como todo o país, possui poucas iniciativas de trabalho prisional. No estado, o número de presos condenados trabalhando é inexpressivo em relação ao quantitativo geral. Em um total de

\footnotetext{
${ }^{5}$ Audiência Pública sobre a Explosividade do Sistema Prisional e a Insegurança da Sociedade Civil, realizada no dia 19 de abril de 2005 na Assembléia Legislativa de Vitória - ES (informação verbal).

${ }^{6}$ Audiência Pública sobre a Explosividade do Sistema Prisional e a Insegurança da Sociedade Civil, realizada no dia 19 de abril de 2005 na Assembléia Legislativa de Vitória - ES (informação verbal).
} 
$5.132^{7}$ presos, apenas $13,45 \%{ }^{8}$ destes exercem alguma atividade de trabalho. As frentes de trabalho no estado ocorrem por iniciativa do próprio preso, do governo ou de empresas privadas.

São 690 presos desenvolvendo atividades profissionais, sendo que a nova Penitenciária de Colatina, PSMECOL, e o PSME II lideram essa iniciativa. As atividades variam desde a realização de artesanato por ação própria dos encarcerados até as iniciativas governamentais e privadas. Percebe-se que as frentes de trabalho atingem uma pequena porcentagem dos encarcerados no estado, e que sua expansão é dificultada, entre outros, pela alta burocracia, no estabelecimento, dos convênios com as empresas e pela falta de infra-estrutura das cadeias.

\section{O egresso}

Os altos índices de reincidência são resultados claros e óbvios de um sistema que, ao invés de reeducar o cidadão, o insere em um aprendizado constante de práticas ilícitas e em uma situação desumana nas prisões. Como exceções a esta desordem do sistema, existem presos que, apesar de inseridos neste ambiente, buscam no trabalho, na religião, na família e em outras bases de sustentação, a sua ressocialização. Sá (2004, p. 27) afirma que "uma vez caído na desconfiança da sociedade, não será fácil mudar seu conceito ou seu 'pensamento'. O egresso caiu neste conceito de desconfiança e a sociedade não lhe facilitará uma mudança, simplesmente".

Ainda de acordo com Sá (2004, p. 33-34), o trabalho dignifica o homem, mas o egresso não carrega a sua dignidade consigo ao sair dos muros da prisão. O emprego torna-se um sonho distante diante da conjuntura atual brasileira, e a sociedade depara-se com um mercado de trabalho em constantes mudanças, que muitas vezes o torna paradoxal, pois também pode se converter "[...] em uma espécie de prisão sem grades e sem tempo determinado para a pena, onde os corpos se tornam dóceis e as almas confusas em troca de uma possibilidade de sobrevivência" (COSTA e BRATKOWSKI, 2004, p. 15).

\section{Metodologia}

Para a classificação da pesquisa, toma-se como base a taxionomia apresentada por Vergara (2004). Quanto aos fins, foi realizada uma pesquisa exploratória, com o objetivo de conhecer as frentes de trabalho desenvolvidas pelas organizações privadas no IRS e na PSME II. Quanto aos meios de investigação foram utilizados a pesquisa bibliográfica e um estudo de caso. Livros, revistas, jornais, redes eletrônicas, contatos telefônicos e pessoais, seminários, audiências públicas foram alternativas para obtenção dos dados necessários ao desenvolvimento deste estudo, além das entrevistas semi-estruturadas.

Desenvolveu-se um estudo de caso nas empresas A e B, inseridas no IRS e na PSME, respectivamente, com a finalidade de conhecer em detalhes as unidades produtivas nos estabelecimentos penais citados. Tal pesquisa não visa apresentar resultados generalizáveis, mas sim, proporcionar uma visão relevante dos objetos de estudo (GIL, 2002). De acordo com Godoy (1995), o foco de uma pesquisa qualitativa é amplo, e a obtenção de dados descritivos faz-se mediante contato direto e interação do pesquisador com a situação. A interpretação da pesquisa surge do entendimento do pesquisador sobre a percepção dos sujeitos quanto aos fenômenos estudados. Percepção que não pode ser quantificada e, sim, percebida em um universo de significados, motivos, aspirações, crenças, valores e atitudes. Assim sendo, o que se mostrou mais apropriado aos objetivos foi o método de estudo de caso, bem como a realização de uma pesquisa qualitativa.

Tem-se como sujeitos desta pesquisa cinco internos e um responsável pela unidade de produção penal de cada uma das empresas pesquisadas. De acordo com Vergara (1998), deve-se verificar os sujeitos de pesquisa ao considerar que estes atenderão o objetivo proposto.

\footnotetext{
${ }^{7}$ Fonte: Diretoria Geral dos Estabelecimentos Penais, DIGESP, Subsecretaria para Assuntos do Sistema Penal, no dia 12 de dezembro de 2005.

${ }^{8}$ Fonte: Informações coletadas em ligações telefônicas realizadas a cada um dos estabelecimentos carcerários e consultas feitas aos seus funcionários em novembro de 2005.
} 
A pesquisa de campo foi estruturada por meio de entrevistas semi-estruturadas, realizadas no período de novembro a dezembro de 2005, gravadas, transcritas e realizadas com os responsáveis pela unidade de produção das empresas. Porém, a observação e os contatos com os profissionais do sistema ocorreram no período de agosto a dezembro de 2005. A escolha dos sujeitos deu-se de forma aleatória e de acordo com as condições do local. É importante ressaltar que as informações foram coletadas em entrevistas com as pessoas responsáveis pelas unidades de produção de ambas as empresas, porém tomam-se os dados informados como referentes às empresas e não às pessoas que as forneceram.

$\mathrm{Na}$ análise e interpretação dos dados, utilizou-se a análise qualitativa de conteúdo, que tem como objetivo "desmontar a estrutura e os elementos desse conteúdo para esclarecer suas diferentes características e extrair sua significação" (LAVILLE e DIONE, 1999, p. 214). Segundo os autores, essa estratégia supõe a definição de categorias analíticas sob as quais o conteúdo é agrupado por parentesco de sentido. Neste trabalho, essas categorias foram definidas a posteriori, ou seja, depois da coleta e organização dos dados obtidos nas entrevistas.

\section{A ótica das empresas}

A análise de dados visa responder as questões traçadas nos objetivos do presente artigo. Cabe ressaltar que, neste trabalho, não se pretende traçar um perfil de todas as inserções privadas no sistema penitenciário, o que se busca é estudar apenas a atuação, neste sistema, das duas empresas já citadas. São apresentados, a seguir, de forma concisa, os resultados comparativos do estudo realizado relativos a cada assunto abordado.

Neste tópico, constam, inicialmente, informações referentes à implantação da unidade de produção no espaço carcerário e, em seguida, a descrição de aspectos gerenciais considerados relevantes para o conhecimento da unidade de produção. Nos aspectos em que se identificou a necessidade de maior compreensão e informação para o leitor, um parágrafo de esclarecimento apresenta-se em seguida ao resultado comparativo. No Quadro 1, a seguir, tem-se, na primeira coluna, o tema pesquisado e, nas segunda e terceira colunas, as análises dos dados relativos à Empresa A e Empresa B, respectivamente.

\section{Quadro 1 - Fatores Motivacionais de Implantação}

\begin{tabular}{lll}
\hline Aspecto Pesquisado & Empresa A & Empresa B \\
\hline $\begin{array}{l}\text { Fatores Motivacionais de } \\
\text { Implantação }\end{array}$ & $\begin{array}{l}\text { Competitividade com preço aliado à } \\
\text { qualidade e à crença no ser humano }\end{array}$ & $\begin{array}{l}\text { Diminuir os custos de produção e } \\
\text { ajudar. }\end{array}$ \\
\hline
\end{tabular}

A idéia de implantação partiu dos proprietários de cada empresa, sendo necessário o auxilio da SEJUS para andamento e efetividade do processo. Percebe-se que a penetração das empresas privadas no sistema deve-se ao esforço da secretaria e da diretoria de cada presídio. As informações referentes a essa inserção, a tramitação de documentos, a escolha do espaço entre as penitenciárias no Estado, também são ações auxiliadas pela SEJUS.

\section{Quadro 2 - Fatores Relacionados à Instalação das Empresas}

\begin{tabular}{lll}
\hline Tempo para instalação & $\begin{array}{l}02 \text { meses. Sendo este o tempo } \\
\text { necessário para aprovação do } \\
\text { convênio. }\end{array}$ & $\begin{array}{l}\text { 06 meses. Acredita-se que este tempo } \\
\text { foi para negociação e valores a serem } \\
\text { pagos. }\end{array}$ \\
\hline $\begin{array}{l}\text { Tempo da Frente de } \\
\text { Trabalho }\end{array}$ & 07 meses & 11 meses \\
\hline Infra-estrutura & $\begin{array}{l}\text { Máquinas de costura, mesa para corte, } \\
\text { rodas de espuma, cavaletes para } \\
\text { acomodação do couro e outros. }\end{array}$ & $\begin{array}{l}\text { Uma plataforma com cadeiras, mesa, } \\
\text { quadro, balanças, caixas e facas para } \\
\text { descascar o alho. }\end{array}$ \\
\hline Reforma & Foi realizada. & Não foi necessária. \\
\hline
\end{tabular}


Ambas as empresas optaram por determinado presídio, levando em consideração a logística necessária, tanto no que diz respeito aos seus empregados, quanto ao material referente à produção. Assim, a Empresa A estabeleceu-se no IRS, o mais antigo presídio construído na Grande Vitória/ES, com necessidade de obras no espaço, as quais foram realizadas pela mão-de-obra indireta dos próprios presos. O PSME II, onde a Empresa B se encontra, foi inaugurado em 2004 com uma estrutura parcialmente preparada para o estabelecimento de frentes de trabalho. Em sua maioria, os presídios não são construídos com o intuito de receber empresas e suas respectivas unidades de produção.

\section{Quadro 3 - Tipo de Produção das Empresas}

\begin{tabular}{lll}
\hline A empresa produz capas de couro para & $\begin{array}{l}\text { Por insuficiência da empresa em } \\
\text { atender a demanda do mercado, a }\end{array}$ \\
Tipo de Produção & $\begin{array}{ll}\text { banco de carros. Dos } 180 \text { modelos da } \\
\text { sede, a unidade produz apenas 22. Um } \\
\text { processo artesanal de riscagem do } \\
\text { couro, acoplagem, corte e costura. }\end{array}$ & $\begin{array}{l}\text { limpeza do alho foi repassada para a } \\
\text { penitenciária. O processo resume-se } \\
\text { em retirar a palha, selecionar o alho e } \\
\text { recolocá-lo na caixa. }\end{array}$ \\
\hline
\end{tabular}

Ao analisar o tipo de produção adotado nas frentes, percebe-se que são seções com características mais padronizadas em relação ao restante da produção na empresa, sem complexidade ou dificuldades. Mais adiante, poder-se-á verificar a percepção dos internos sobre a qualificação adquirida e sua efetiva utilização no mercado de trabalho. Vale adiantar que tais aspectos foram levantados apenas por uma empresa e seus respectivos empregados.

O auxílio imediato representado pela satisfação da ocupação do tempo e pela remuneração pode se tornar ponto crítico gerador de frustração no reencontro com o mercado. Cabe questionar até que ponto a qualificação em trabalhos que dependam da iniciativa privada, ou de qualquer outro setor, colabora para que os egressos consigam se estabilizar no retorno ao mercado. Não há contrariedade à inserção destas frentes de trabalho, porém a submissão e o respeito a tais práticas não podem existir apenas porque elas exercem o bem a pessoas que estão às margens da lei. Não se deve contentar-se com o mínimo, mas sim, com o que é de direito.

\section{Quadro 4 -Fatores Relacionados à Capacidade, Crescimento e Remuneração}

\begin{tabular}{lll}
\hline $\begin{array}{l}\text { Capacidade de Produção da } \\
\text { unidade }\end{array}$ & $\begin{array}{l}80 \text { capas mensais, podendo atingir, } \\
\text { com a capacidade instalada, 150 capas. }\end{array}$ & $\begin{array}{l}18 \text { quilos por hora, o que corresponde } \\
\text { a 14,4 caixas por hora e, portanto, } \\
2.304 \text { caixas por mês. }\end{array}$ \\
\hline $\begin{array}{l}\text { Perspectiva de Crescimento } \\
\text { da Frente de Trabalho }\end{array}$ & $\begin{array}{l}\text { Manterá a produção na sede e ampliará } \\
\text { a produção carcerária de acordo com a } \\
\text { demanda do mercado. }\end{array}$ & $\begin{array}{l}\text { Planeja transferir toda a parte de } \\
\text { azeitonas, que é feita na empresa, } \\
\text { assim como a embalagem destes, para } \\
\text { a unidade carcerária. }\end{array}$ \\
\hline $\begin{array}{l}\text { Remuneração } \\
\text { Salário mínimo fixo + Remuneração }\end{array}$ & $\begin{array}{l}\text { Salário mínimo fixo + Remuneração } \\
\text { variável atrelada à produtividade } \\
\text { individual. }\end{array}$ \\
\hline
\end{tabular}

A remuneração não é um fator presente em todas as frentes de trabalho no sistema carcerário. A atividade sem remuneração, além da remição da pena, representa aos internos uma oportunidade de visualização perante a diretoria do presídio de que estão preparados e dispostos ao trabalho. De acordo com os internos, essas atividades servem de acesso ao trabalho remunerado, o que pode ser considerado como um período de préseleção para as frentes remuneradas, fato relevante no processo de seleção dos internos. 


\section{Quadro 5 - Fatores Relacionados ao Cotidiano do Trabalho}

\begin{tabular}{lll}
\hline Seleção dos Internos & $\begin{array}{l}\text { Realizada pela direção do presídio em } \\
\text { parceria com a SEJUS. A empresa } \\
\text { apenas solicitou ponderação em } \\
\text { relação à aptidão dos candidatos para o } \\
\text { trabalho manual. }\end{array}$ & $\begin{array}{l}\text { Realizada pela direção do presídio em } \\
\text { parceria com a SEJUS. Não houve } \\
\text { exigência de pré-qualificação. }\end{array}$ \\
\hline Internos empregados & Dez & Nove \\
\hline $\begin{array}{l}\text { Treinamento para } \\
\text { realização do trabalho }\end{array}$ & $\begin{array}{l}\text { Os trabalhos se iniciaram junto com o } \\
\text { treinamento realizado por um técnico } \\
\text { da empresa. }\end{array}$ & $\begin{array}{l}\text { Um encarregado de produção da sede } \\
\text { esteve presente no início da produção } \\
\text { para ensiná-los. }\end{array}$ \\
\hline $\begin{array}{l}\text { Acompanhamento Diário } \\
\text { da Produção }\end{array}$ & $\begin{array}{l}\text { Há um supervisor que acompanha de } \\
\text { forma presencial, dia a dia, a } \\
\text { produção. }\end{array}$ & $\begin{array}{l}\text { Um interno é responsável pelo } \\
\text { controle através de planilhas de } \\
\text { produtividade, detalhando a produção } \\
\text { por interno a cada hora. }\end{array}$ \\
\hline $\begin{array}{l}\text { Uniformes } \\
\text { Relacionamento entre } \\
\text { empresa e interno }\end{array}$ & $\begin{array}{l}\text { Camisa e calça. } \\
\text { dia-a-dia da frente, assim como } \\
\text { também não há na sede da empresa. }\end{array}$ & $\begin{array}{l}\text { Camisa, touca e máscara. } \\
\text { interno são políticas comuns à sede da } \\
\text { empresa e à unidade carcerária. }\end{array}$ \\
\hline $\begin{array}{l}\text { Egresso em relação à } \\
\text { empresa }\end{array}$ & $\begin{array}{l}\text { Não há intenção por parte da empresa } \\
\text { em absorver a mão-de-obra egressa. }\end{array}$ & $\begin{array}{l}\text { Não é intenção pela empresa de } \\
\text { absorção da mão-de-obra egressa }\end{array}$ \\
\hline
\end{tabular}

As empresas afirmam que o trabalho direcionado aos internos é uma iniciativa importante e que lhes servirá ao retorno no mercado de trabalho.

[...] mas, o estilo de trabalho nosso permite que essas pessoas possam ser aproveitadas em outros setores, em outros campos de trabalho nosso. [...] Porque eles estão adquirindo é capacitação profissional, e bastante. Qualificação total, com certeza. Só isso aí já é um grande ganho. [Empresa A]

[...] eles pensarem que o mesmo ritmo de trabalho aqui [sede] é o mesmo aplicado com eles lá [penitenciária]... não tem nada de diferença, ou mais ou menos... não é muito diferente de lá [penitenciária] e aqui [sede], e ao mesmo tempo eles têm rotina de trabalho, isso está contribuindo para quando eles forem sair. Porque alguns têm penas longas, mas de qualquer forma a cabeça ali não está obsoleta, né... estão trabalhando, têm aquela rotina de trabalho... [Empresa B]

Se não há absorção desta mão-de-obra por estas empresas que se colocam na posição de romper as dificuldades e as barreiras do preconceito ao se estabelecerem dentro do sistema, que empresa absorverá tal mão-de-obra ao ponderar que pequena parte da população envolve-se e conhece as iniciativas positivas, ainda que tímidas, do sistema carcerário?

No Quadro 6, a seguir, ao citar o marketing social, vale analisar como o papel social se encaixa em tais ações desenvolvidas pelas empresas.

\section{Quadro 6-Marketing Social}

\begin{tabular}{lll}
\hline Marketing Social & $\begin{array}{l}\text { Pretender divulgar sua unidade de } \\
\text { produção carcerária em seu site. }\end{array}$ & $\begin{array}{l}\text { Divulga internamente no jornal da } \\
\text { empresa. }\end{array}$ \\
\hline
\end{tabular}

Além da ocupação do tempo, remuneração, adaptabilidade às rotinas, o trabalho inserido nas penitenciárias tem a responsabilidade de prepará-los para o futuro além das grades. A preparação, qualificação e/ou requalificação são fatores fundamentais na busca de um trabalho extra-muros. 
Tornar-se competitivo frente ao mercado utilizando mão-de-obra carcerária barata não é mérito e não representa um papel social. A simples execução do trabalho prisional não significa a adoção de uma ação filantrópica. A crença e a valorização no ser humano devem ultrapassar meros intuitos produtivos e lucrativos e atender as verdadeiras práticas da ressocialização do homem encarcerado.

\section{A ótica dos internos}

Esta seção da análise dos resultados é composta de três partes. Inicialmente, tem-se o perfil dos sujeitos entrevistados. Em seguida, descreve-se a percepção dos presos da frente de trabalho sobre sua recolocação no mercado de trabalho. No segundo apontamento, tem-se a análise dos internos em conjunto e, uma análise posterior, de acordo com as frentes de trabalho desenvolvidas por cada um dos dois grupos. Já em relação à percepção dos presos quanto às frentes de trabalho no cotidiano do cumprimento da pena, a terceira parte desta análise considera o grupo analisado como um só universo e descreve assuntos relevantes, deste cotidiano, influenciados ou não pelo trabalho.

\section{Perfil dos internos}

Após a realização das entrevistas e visando um maior conhecimento sobre os sujeitos entrevistados, traçou-se o perfil de acordo com idade, grau de escolaridade, reincidência, data da prisão, duração da pena e descrição do delito cometido. Os sujeitos da pesquisa são identificados por números de acordo com a legenda no Quadro 7. A numeração adotada de um a cinco refere-se aos internos da frente de trabalho da Empresa A no IRS; enquanto a numeração de seis a dez, à outra frente pesquisada, a Empresa B no PSME II.

\section{Quadro 7 - Perfil dos Internos}

\begin{tabular}{|c|c|c|c|c|c|c|}
\hline Interno & $\begin{array}{l}\text { Idade } \\
\text { (Anos) }\end{array}$ & $\begin{array}{l}\text { Grau de } \\
\text { Escolaridade }\end{array}$ & Reincidente & $\begin{array}{l}\text { Prisão no } \\
\text { dia }\end{array}$ & $\begin{array}{l}\text { Duração } \\
\text { da Pena }\end{array}$ & Delito \\
\hline Interno 1 & 42 & $\begin{array}{l}\text { Superior } \\
\text { Incompleto }\end{array}$ & Não & $14 / 3 / 2000$ & $10 \mathrm{a}$ & $\begin{array}{l}\text { Tráfico de entorpecentes e } \\
\text { associação de uma ou mais } \\
\text { pessoas com finalidade de praticar } \\
\text { tráfico. }\end{array}$ \\
\hline Interno 2 & 30 & $\begin{array}{l}\text { Fundamental } \\
\text { Incompleto }\end{array}$ & Não & 18/06/1997 & $18 \mathrm{a} 6 \mathrm{~m}$ & Homicídio e Furto \\
\hline Interno 3 & 46 & $\begin{array}{l}\text { Fundamental } \\
\text { Incompleto }\end{array}$ & Não & 08/10/1999 & $20 \mathrm{a}$ & Roubo \\
\hline Interno 4 & 35 & $\begin{array}{l}\text { Médio } \\
\text { Incompleto }\end{array}$ & Não & $15 / 01 / 2002$ & $\begin{array}{l}15 \mathrm{a} 2 \mathrm{~m} \\
333 \mathrm{~d}\end{array}$ & $\begin{array}{l}\text { Adulteração, Falsificação e } \\
\text { Causar incêndio. }\end{array}$ \\
\hline Interno 5 & 31 & $\begin{array}{l}\text { Fundamental } \\
\text { Incompleto }\end{array}$ & Não & $16 / 08 / 2003$ & $6 a$ & Atentado Violento ao Pudor \\
\hline Interno 6 & 36 & $\begin{array}{l}\text { Médio } \\
\text { Completo }\end{array}$ & Não & $20 / 02 / 2000$ & $12 \mathrm{a}$ & Homicídio \\
\hline Interno 7 & 47 & $\begin{array}{l}\text { Fundamental } \\
\text { Incompleto }\end{array}$ & Sim & $01 / 05 / 2003$ & 4a $50 \mathrm{~d}$ & Tráfico de entorpecentes \\
\hline Interno 8 & 40 & $\begin{array}{l}\text { Médio } \\
\text { Completo }\end{array}$ & Não & $18 / 03 / 2004$ & $10 \mathrm{a} 7 \mathrm{~m}$ & $\begin{array}{l}\text { Estelionato e formação de } \\
\text { quadrilha }\end{array}$ \\
\hline Interno 9 & 60 & Analfabeto & Não & $15 / 07 / 2001$ & $18 \mathrm{a}$ & Homicídio \\
\hline Interno 10 & 29 & $\begin{array}{l}\text { Fundamental } \\
\text { Incompleto }\end{array}$ & Não & 17/06/1999 & $12 \mathrm{a} 6 \mathrm{~m}$ & Homicídio e Furto \\
\hline
\end{tabular}

Obs: Na coluna Duração da Pena, "a" representa anos, "m” significa meses e "d" dias. 


\section{A recolocação no mercado de trabalho}

Abaixo, a Figura 1 aponta três perspectivas adotadas para a análise dos dados obtidos sobre o trabalho prisional. A primeira refere-se ao trabalho realizado antes da prisão e à semelhança com os trabalhos desenvolvidos nas frentes de trabalho carcerárias. Na segunda perspectiva proposta, analisa-se a influência do trabalho realizado dentro da prisão, bem como sua correlação com o futuro pretendido e esperado pelos internos. Sob a terceira e última perspectiva, apresenta-se uma análise sobre a ligação do trabalho realizado antes da prisão e seu futuro trabalho pretendido.

\section{Figura 1 - Perspectivas de Análise}

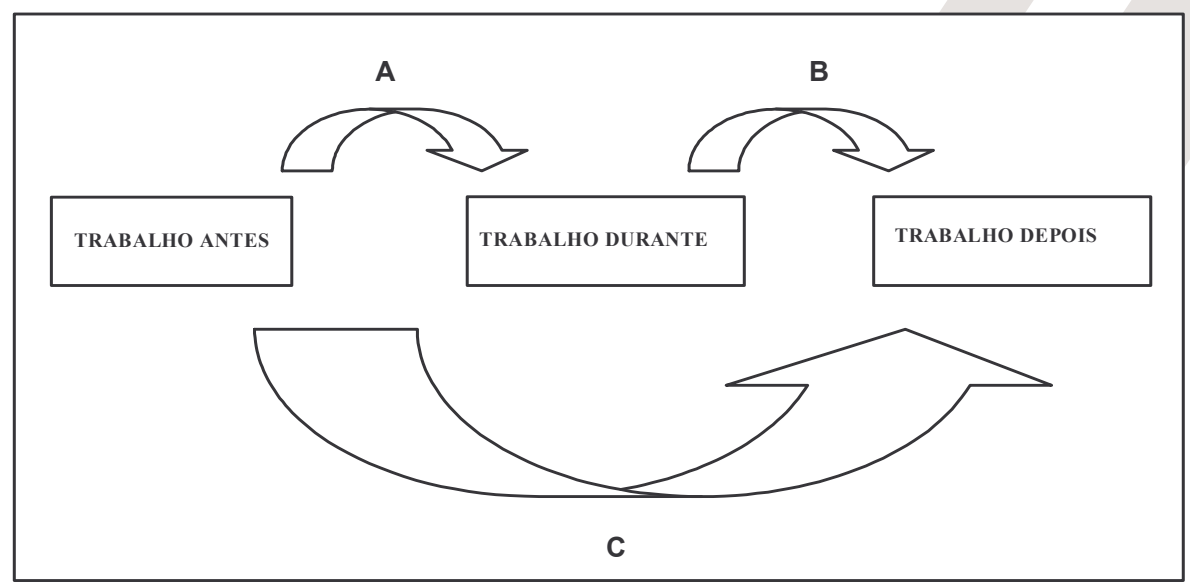

A seguir um quadro com os trabalhos desenvolvidos pelos internos antes e durante a prisão e suas pretensões em relação à recolocação no mercado de trabalho.

\section{Quadro 8 - Trabalhos Realizados pelos Internos no Sistema Penitenciário}

\begin{tabular}{llll}
\hline Interno & $\begin{array}{l}\text { Trabalhos desenvolvidos } \\
\text { antes da prisão }\end{array}$ & $\begin{array}{l}\text { Trabalhos desenvolvidos no } \\
\text { cumprimento da pena }\end{array}$ & $\begin{array}{l}\text { Percepção do auxílio da } \\
\text { frente de trabalho em sua } \\
\text { recolocação no mercado }\end{array}$ \\
\hline Interno 1 & $\begin{array}{l}\text { Tesoureiro de carro forte, } \\
\text { carreteiro. }\end{array}$ & $\begin{array}{l}\text { Capina, tecelagem de redes, } \\
\text { ajudante de cozinha. }\end{array}$ & $\begin{array}{l}\text { Pretende seguir sua profissão } \\
\text { antiga, mas afirma ter } \\
\text { adquirido uma nova profissão e } \\
\text { considera uma oportunidade de } \\
\text { trabalho na Empresa A. }\end{array}$ \\
\hline
\end{tabular}

\begin{tabular}{llll}
\hline Interno 2 & $\begin{array}{l}\text { Motorista, ajudante de } \\
\text { eletricista em casa de material } \\
\text { de construção e depósito de } \\
\text { bebida. }\end{array}$ & $\begin{array}{l}\text { Artesanato, confecção artesanal } \\
\text { de bolas, produção de } \\
\text { embalagens de isopor, } \\
\text { estofaria, estamparia, empresa } \\
\text { de construção civil. }\end{array}$ & $\begin{array}{l}\text { Possibilidade de arrumar } \\
\text { trabalho na Empresa A. }\end{array}$ \\
\hline Interno 3 & $\begin{array}{l}\text { Proprietário de oficina } \\
\text { mecânica. }\end{array}$ & $\begin{array}{l}\text { Confecção artesanal de bolas, } \\
\text { estamparia, manutenção de } \\
\text { carros e serviços externos para } \\
\text { o presídio. }\end{array}$ & $\begin{array}{l}\text { Primeiramente um negócio } \\
\text { próprio e, caso tenha algum } \\
\text { empecilho, procurar } \\
\text { oportunidade de trabalho na } \\
\text { Empresa A. }\end{array}$ \\
\hline
\end{tabular}




\begin{tabular}{|c|c|c|c|}
\hline Interno 4 & $\begin{array}{l}\text { Motorista de ônibus escolar e } \\
\text { particular, pedreiro e } \\
\text { proprietário de oficina de } \\
\text { lanternagem e pintura de } \\
\text { veículos. }\end{array}$ & $\begin{array}{l}\text { Confecção artesanal de bolas, } \\
\text { faxina e artesanato. }\end{array}$ & $\begin{array}{l}\text { Possibilidade de trabalhar na } \\
\text { Empresa A e se possível } \\
\text { adaptar a parte da produção } \\
\text { aprendida (capotagem) em seu } \\
\text { negócio próprio. }\end{array}$ \\
\hline Interno 5 & $\begin{array}{l}\text { Office-boy, serralheiro, } \\
\text { padeiro, pedreiro e gari. }\end{array}$ & Reciclagem e artesanato. & $\begin{array}{l}\text { Possibilidade de trabalhar na } \\
\text { Empresa A ou retornar à } \\
\text { profissão anterior. }\end{array}$ \\
\hline Interno 6 & $\begin{array}{l}\text { Vendedor, controlador de } \\
\text { cargas no porto. }\end{array}$ & $\begin{array}{l}\text { Fábrica de jeans, tecelagem de } \\
\text { redes e tarrafa artesanal. }\end{array}$ & $\begin{array}{l}\text { Rotina de trabalho e instrução } \\
\text { adquirida. }\end{array}$ \\
\hline Interno 7 & $\begin{array}{l}\text { Contratado por terceirizada na } \\
\text { CST e proprietário de loja de } \\
\text { calçados. }\end{array}$ & $\begin{array}{l}\text { Construção de muro do } \\
\text { presídio. }\end{array}$ & $\begin{array}{l}\text { Possibilidade de conseguir } \\
\text { trabalho na Empresa B, ou ao } \\
\text { menos uma carta de } \\
\text { recomendação. }\end{array}$ \\
\hline Interno 8 & $\begin{array}{l}\text { Office-boy, funcionário público } \\
\text { e vendedor. }\end{array}$ & Não realizou nenhum trabalho. & $\begin{array}{l}\text { Apenas uma experiência e } \\
\text { habilidade que não será } \\
\text { utilizada. }\end{array}$ \\
\hline Interno 9 & Rural & $\begin{array}{l}\text { Trabalho atual é o primeiro, } \\
\text { não realizou nenhum outro. }\end{array}$ & $\begin{array}{l}\text { Aprendizado para uso em seu } \\
\text { próprio plantio. }\end{array}$ \\
\hline Interno 10 & $\begin{array}{l}\text { Empacotador de supermercado } \\
\text { e soldador }\end{array}$ & $\begin{array}{l}\text { Trabalho atual é o primeiro, } \\
\text { não realizou nenhum outro. }\end{array}$ & $\begin{array}{l}\text { Possibilidade de conseguir } \\
\text { trabalho na Empresa B. }\end{array}$ \\
\hline
\end{tabular}

Os trabalhos que os internos executam pela Empresa A são de marcação do couro e corte (Interno 1), costura (Internos 2, 3 e 4) e acoplagem das peças do banco (Interno 5). Já na Empresa B, os internos realizam a função de descascar alho (Internos 6, 7, 9 e 10) e controle e abastecimento da produção (Interno 8).

Na primeira perspectiva de análise, percebe-se que, apenas nos trabalhos desenvolvidos pelo interno 3, há a aplicação do conhecimento adquirido em seu trabalho anterior à prisão. $\mathrm{O}$ seu conhecimento com manutenção em veículos, por ter sido proprietário de oficina mecânica, deu-lhe possibilidade de atuação dentro do presídio, conseguindo a oportunidade de trabalho com a manutenção dos veículos do próprio estabelecimento carcerário. Os demais internos desenvolveram e/ou desenvolvem funções que não possuem ligação direta com suas atuações profissionais passadas. Percebe-se a não adaptabilidade do trabalho carcerário à sua mão-de-obra e, sim, o contrário. Os trabalhos artesanais são os que mais se destacam em atuação e podem ser usados como exemplo. Muitos dos encarcerados quando em liberdade nunca tiveram contato com tal habilidade, que acabou por ser percebida e colocada em prática.

Ao serem questionados sobre a pretensão de trabalho quando egressos, apenas o interno 6 demonstrou não ter clara visão quanto à recolocação no mercado - diferentemente dos outros internos, que apresentaram planos e expectativas para o futuro, descrevendo um ou mais caminhos para o alcance do trabalho. Nas duas próximas perspectivas, são analisadas todas as possibilidades apontadas pelos internos para o restabelecimento no mercado. No Quadro 8, estão descritas de acordo com o que aparecia nos relatos; mas, nesta análise, apresentam o mesmo grau de importância.

A segunda perspectiva de análise proposta refere-se à influência do trabalho carcerário quanto à recolocação no mercado. Os internos 4 e 9 apresentam intenções de aproveitamento do conhecimento adquirido e aplicação em seus próprios negócios.

Observa-se que os internos 1, 2, 3, 4, 5, 7 e 10 demonstram expectativas de acolhimento pelas empresas ao fim da pena - sendo dois empregados da Empresa B e cinco da Empresa A - estes últimos fazem menção direta ao proprietário da empresa. A questão, nesse caso, é que as empresas estudadas foram incisivas em suas 
afirmações sobre a não absorção da mão-de-obra egressa do sistema, Ao mesmo tempo esta mão-de-obra fomenta expectativas e ilusões para o futuro com foco nas contratantes, ao considerar possibilidades de extensão deste elo no trabalho. Pondera-se que as empresas, uma vez dentro do estabelecimento penal, estabelecem vínculos e imagens de credibilidade e valorização do preso perante os internos, tornando-se muito mais próximas e atuando como ponto de referência para o trabalho. Porém, cabe ressaltar que alguns posicionamentos das empresas tornam-se equivocados e devem ser cautelosos, para que não haja problemas futuros. Diante de um mercado de trabalho extremamente restrito aos egressos do sistema penitenciário, os internos acreditam que um bom desenvolvimento na frente de trabalho lhes fornecerá uma oportunidade de inserção na respectiva contratante. Além disso, a política de não absorção da mão-de-obra gera alguns pontos contraditórios, uma vez que se forma um profissional que vem a ser denominado qualificado, mas que, no entanto, não é aproveitado.

Na terceira perspectiva desta análise, retrata-se a relação entre os trabalhos anterior e posterior à prisão. Percebe-se, por exemplo, que os internos 1, 3, 5, 8 e 9 não visualizam um trabalho futuro influenciado pelas frentes carcerárias desenvolvidas. Fator que contraria o discurso do trabalho carcerário como apoio à profissionalização com intuito de reinserir os internos na sociedade, e, portanto no trabalho. É importante ressaltar que se trata de uma análise sobre a perspectiva deste preso quanto à recolocação no mercado de trabalho; desse modo, não se pretende nem se pode descrever as reais influências no futuro destes presos.

\section{O cotidiano do cumprimento da pena}

A terceira e última análise neste estudo possui como foco a descrição da percepção dos presos sobre as relações de trabalho no cotidiano do cumprimento da pena. Para esta análise, como já foi relatado, tem-se todos os grupos de internos, dos dois presídios, em análise. No Quadro 9, são citados os principais fatores considerados relevantes.

\section{Quadro 9 - Aspectos Relevantes do Cotidiano da Pena}

\section{Aspectos Relatados}

Os anos de encarceramento tornam-se anos irrecuperáveis na visão da pessoa presa, momento em que a vida perde a continuidade, estagna-se ou retrocede. Os internos apresentam em suas

O tempo falas a importância do trabalho como fator atenuante do passar do tempo dentro da cadeia, tanto como fator de redução da pena através da remição, quanto do tempo vivenciado dentro do espaço carcerário. O tempo aliado ao ócio é considerado um dos componentes mais negativos dentro do cárcere.

O ócio é um fator extremamente presente no dia-a-dia do encarcerado, e cabe ressaltar que

O ócio pensamentos e práticas de estímulo à violência são fatores comumente gerados pela ociosidade.

Ambiente Percebe-se que as frentes de trabalho carcerárias tornam-se uma fuga ao ambiente das celas, Carcerário espaço considerado como celeiro de maus pensamentos.

Independente de como sustentavam a família e a si mesmos, estando presos esta possibilidade

Remuneração torna-se quase nula, devido às tímidas iniciativas de frentes de trabalho existentes. Portanto, muitos deles afirmam a necessidade desse dinheiro para auxiliar as famílias e a sobrevivência dentro do presídio.

Adquirir uma nova profissão e a esperança de aplicá-la no retorno ao mercado de trabalho tornam-se um considerável estímulo para o desempenho das atividades. Cabe observar que a

Qualificação qualificação não esteve presente nas considerações feitas pelos internos que trabalham para a Empresa B, nem pela própria empresa. $\mathrm{O}$ aprendizado, assim como a manutenção do conhecimento, faz-se necessário e torna-se um ponto de apoio para os internos. 


\section{Trabalho \\ Intrínseco ao \\ Homem}

O trabalho exerce sobre estes homens encarcerados o papel de resgate da dignidade e é uma demonstração de que os valores pessoais não estão atrelados ao motivo da condenação. Muitos afirmam, ao serem questionados sobre o motivo pelo qual buscam o trabalho, que esta é uma atividade intrínseca ao homem e apontam sua realização como prática louvável e prazerosa.

\section{A oportunidade de trabalho no sistema carcerário é vista pelos internos como um processo de reconhecimento. Nesta relação de trabalho oferecido aos presos e intermediado ou concedido pelo pela diretoria do presídio, estão envolvidos valores como confiança e votos de credibilidade. Trabalho Percebe-se que os internos consideram que a condenação representa o fim de seus valores pessoais, o início de um preconceito e a perda do reconhecimento como ser humano.}

\begin{tabular}{ll}
$\begin{array}{l}\text { Ampliação do } \\
\text { Ciclo de }\end{array}$ & $\begin{array}{l}\text { As duas unidades carcerárias estudadas mantêm os presos nas celas apenas no período da } \\
\text { noite, e durante o dia as grades são abertas para que estes possam circular dentro de suas } \\
\text { Amizades }\end{array}$ \\
$\begin{array}{l}\text { respectivas galerias. Com isso, os contatos se restringem a presos de mesma galeria, barreira } \\
\text { que pode ser ultrapassada no ambiente de trabalho. }\end{array}$ \\
$\begin{array}{l}\text { Visão do } \\
\text { Trabalho }\end{array}$ & $\begin{array}{l}\text { Cooperação entre empregados e com a empresa como um todo são características necessárias } \\
\text { a todas as organizações. }\end{array}$ \\
\hline
\end{tabular}

Os dois estabelecimentos penitenciários onde se encontram as frentes de trabalho pesquisadas possuem salas de aula onde os internos interessados podem completar seus estudos. Ambas as

Trabalho e empresas apresentam uma carga de trabalho que preenche o dia todo., Como as aulas são Educação ministradas durante o dia e não pela noite, momento em que os internos estão recolhidos em suas celas, o trabalho torna-se um impedimento para o estudo na prisão. Este fato é relatado por alguns internos.

\section{Considerações finais}

Este estudo teve como objetivo analisar o impacto das frentes de trabalho das organizações privadas sobre os detentos e as organizações que as promovem em dois estabelecimentos penais no Estado do Espírito Santo, o IRS e a PSME II. Para isso, estabeleceram-se enfoques específicos na análise das organizações e presos. Sob a ótica da organização, pretendeu-se descrever a possibilidade de implantação e manutenção, com caracterização sobre os aspectos gerenciais considerados relevantes, das frentes de trabalho das empresas A e B instaladas dentro dos respectivos estabelecimentos penais citados. Em relação à descrição sob a ótica dos presos, procurou-se relatar a percepção destes sobre o impacto da frente de trabalho no cotidiano da pena e em sua recolocação no mercado.

As organizações privadas estudadas apontam o fator competitividade pelo preço como motivo principal para a inserção neste sistema. Longe dos altos encargos trabalhistas e de custos indiretos da produção, essas organizações estabelecem-se dentro das penitenciárias que favorecem a sua logística e instalam as estruturas necessárias de produção.

Cabe observar que as inserções destas frentes de trabalho nas prisões ocupam o tempo ocioso dos presos, retiram-nos do ambiente das celas, contribuem financeiramente para os presos e suas famílias, estimulam a readaptação aos ambientes de trabalho, mas deixam a desejar no que diz respeito à formação de profissionais qualificados para a competição por (re)colocação no mercado de trabalho. De acordo com a pesquisa realizada, poucos foram os presos que, em seus relatos, indicaram que essas atividades podem influenciar ou auxiliar no reencontro, futuramente, com o mercado de trabalho. O mais preocupante é que estes presos criam laços de trabalho com as empresas dentro do sistema, como se estas fossem acolhê-los ao saírem da prisão. Em conflito com essa esperança e ilusão criada estão as empresas que não apresentam políticas para a absorção desta mãode-obra. Forma-se uma mão-de-obra, se não qualificada, ao menos treinada, mas que interessa apenas no momento em que sobre ela não recaem maiores custos de produção. Assim, é necessário que se reflita sobre a 
responsabilidade social desenvolvida pelas empresas e se analisem tanto o alcance do objetivo de sua atuação, como o papel do Estado na aprovação da inserção de empresas que fogem aos objetivos de ressocialização.

Como observado, as frentes de trabalho para os internos representam um grande ponto de apoio para a sobrevivência na reclusão. O trabalho proporciona momentos de fuga ao ócio e ao ambiente das galerias e celas, além de ser um auxílio financeiro. É perceptível nos relatos dos presos que o trabalho traz muita satisfação. Em uma condenação que, além da liberdade, lhes tira a identidade e dignidade, as frentes de trabalho oferecem a estes presos aspectos como oportunidade de profissionalização, novas amizades, valorização, respeito e esperança.

No presente artigo, foram contempladas, como foco de estudo, duas iniciativas privadas no Estado do Espírito Santo - Brasil. Desse modo, não se deve generalizar os resultados obtidos. Este fato pode ser considerado como limitação dos resultados, que indicam, no entanto, novas fontes de pesquisa. Futuros estudos com foco em frentes de trabalho por iniciativas governamentais e dos próprios presos podem se tornar fonte de pesquisa e comparação. Além desta possibilidade, a posterior análise e o acompanhamento do egresso em seu reencontro com o mercado podem corroborar, ou não, os resultados apontados. 


\section{Referências}

BRASIL. Constituição Federal, Código Penal, Código de Processo Penal. 6. ed. São Paulo: Editora Revista dos Tribunais, 2004.

COSTA, Alexandre Marino. 0 trabalho prisional e a reintegração social do setento. Florianópolis: Insular, 1999.

COSTA, Silvia Generalida; BRATKOWSKI, Pedro Luiz da Silva. Paradoxos do trabalho prisional na era do capitalismo flexível: 0 caso Detran - RS. Disponivel em: <http://anpad.org.br/enanpad2004>. Acesso em: 4 maio 2005.

CUSTO de preso vai de flat de luxo a suite cinco estrelas. 0 Povo, Fortaleza, 25 nov. 2005. Disponivel em: <http://www.noolhar.com/opovo/brasil/539583.html> . Acesso em: 27 nov. 2005.

DI PIETRO, Maria Silvia Zanella. Direito Administrativo. 12. ed. São Paulo: Atlas, 2000.

FELIZ, Cláudia. Cadeias estão lotadas de "esquecidos" da justiça. A Gazeta, Vitória, p. 4, 29 maio 2005.

FOUCAULT, Michel. Vigiar e punir: nascimento da prisão. 14. ed. Petrópolis: Vozes, 1996.

GIL, Antônio Carlos. Como elaborar projetos de pesquisas. 4. ed. São Paulo: Atlas, 2002.

GODOY, A S. Pesquisa qualitativa: tipos fundamentais. Revista de administração de empresas, São Paulo, v. 35, 1995.

JOHNSON, Allan G. Dicionário de Sociologia: guia prático da linguagem sociológica. Rio de Janeiro: Jorge Zahar Editor, 1995.

LAVILLE, C; DIONNE, J. A construção do saber: manual de metodologia da pesquisa em ciências humanas. Belo Horizonte: Editora UFMG, 1999.

LEMGRUBER, Julita. 2053: Uma população atrás das grades, Rio de Janeiro, 1997. Disponível em: <http://www.ucam.edu.br/cesec/artigos/Midia_body_JL10.htm>. Acesso em: 27 ago. 2005.

LEMOS, Ana Margarete; MAZZILLI, Cláudio; KLERING, Luis Roque. Análise do trabalho prisional: um estudo exploratório. Disponivel em: http://anpad.org.br>. Acesso em: 19 jun. 2005.

MELLO Renata. Educação e trabalho dentro dos presídios. Revista Reação, Vitória-ES, n. 3, p. 8-9, maio 2005.

MIRABETE, Julio Fabbrini. Execução Penal: comentários à Lei n. 7.210, de 11-7-1984. 10. ed. São Paulo: Atlas, 2002.

PASTORE, José. 0 alcance do trabalho prisional. São Paulo, 2001. Disponivel em: <http://www.josepastore.com.br/artigos>. Acesso em: 24 set. 2005.

RIBEIRO, Ludmila Mendonça Lopes; CRUZ, Marcus Vinicius Gonçalves. Trabalho prisional como política pública de recuperação do criminoso: estudo de múltiplos casos em unidades penitenciárias de Minas Gerais - Brasil. Disponível em: <http://anpad.org.br/enanpad2002>. Acesso em: 19 jun. 2005.

SÁ, Matilde Maria Gonçalves de. 0 egresso do Sistema Prisional no Brasil. São Paulo: Paulistanajur Edições, 2004.

SILVA, Roberto da. 0 que as empresas podem fazer pela reabilitação do preso. São Paulo, 2001. Disponível em: $<$ http://www.ethos.org.br/>. Acesso em: 15 abr. 2004.

VARELLA, Drauzio. Estação Carandiru. 6. ed. São Paulo: Companhia das Letras, 1999.

VERGARA, Sylvia Constant. Projetos e relatórios de pesquisa em administração. 5. ed. São Paulo: Atlas, 2004. 